\title{
Correspondence
}

\section{Intralenticular haemorrhage complicating pulsed laser iridotomy}

SIR, The pulsed laser has recently been described as a 'nonsurgical' means of producing a peripheral iridotomy. The complications of this procedure have been reviewed ${ }^{1}$ and include iritis, pigment dispersion, haemorrhage, transient elevation of intraocular pressure, corneal or lens damage, lack of patency of the iridotomy, and blurring of vision. We report a case in which Q-switched neodymium (Nd)-YAG iridotomy was complicated by intralenticular haemorrhage.

\section{Case report}

A 69-year-old female patient underwent a left trabeculectomy for primary open angle glaucoma which had not responded to conventional medical treatment. Postoperatively it was noted that the pigment layer of the iris remained intact, and pulsed laser treatment was considered necessary to complete the iridectomy.

A Biophysic Médical Q-switched Nd-YAG laser was used in its fundamental mode at an $18^{\circ}$ convergence angle. Ten lesions were applied at $2 \mathrm{~mJ}$ in the mid portion of the iridotomy, aiming at the pigment layer on each occasion. Each shot produced a minute hole. Persistent bleeding had been a problem during surgery and had resulted in a $1.5 \mathrm{~mm}$ hyphaema. The iridotomy was also complicated by haemorrhage. However, tests of blood clotting were all within the normal range. Following this procedure it was noticed that intralenticular haemorrhage had taken place (Figure). This had remained unchanged in character for two months, and the current visual acuities are 6/9 (corrected) left and right.

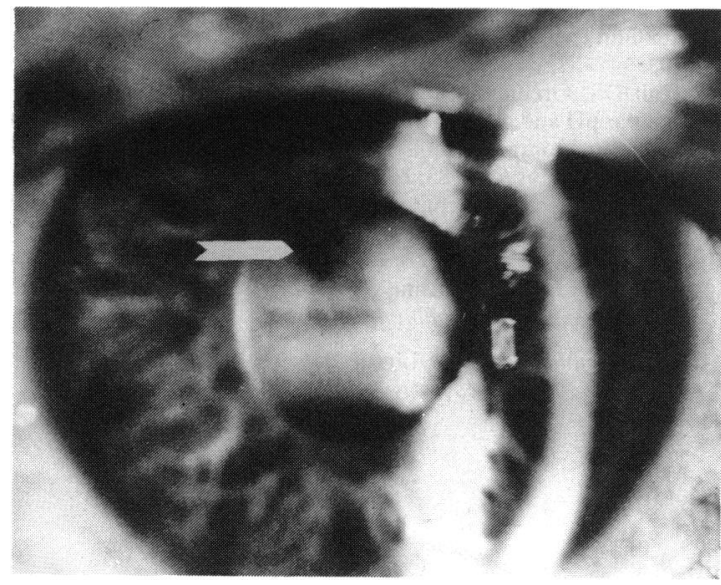

We presume that the laser pulses resulted in microscopic rupture of the lens capsule which has subsequently sealed spontaneously. The haemorrhage within the lens is discrete, lamellar, and lies deep to clear cortical lens material. This appearance would suggest that blood entered the lens by a capillary effect while there was a breach in the capsule and flowed between the lamellae of the lens cortex.

This complication could have been avoided by applying the laser treatment more peripherally. This case highlights the fact that the lesions produced by a pulsed laser are not discrete and that underlying tissues can be damaged. We believe that this is the first reported case of discrete intralenticular haemorrhage caused by Q-switched $\mathrm{Nd}$ YAG laser treatment. DONALD M I MONTGOMERY Tennent Institute of Opthalmology, GORDON N DUTTON Western Infirmary,

Glasgow G11 6NT

\section{Reference}

1 Steinert RF, Puliafito CA. The Nd-YAG laser in ophthalmology. Principles and clinical application of photodisruption. Philadelphia: Saunders, 1985: 102-114.

\section{Notes}

\section{Orthoptic congress}

The Sixth International Orthoptic Congress and Trade Exhibition will take place at Harrogate on 29 June-4 July. It will be opened by Princess Anne. Details from Mrs J Clayton, Chairman of Organising Committee, British Orthoptic Society, Tavistock House North, Tavistock Square, London WC1H 9HX.

\section{Hoyt chair}

Fellows, students, colleagues, and friends of Dr William F Hoyt are in the process of establishing an endowed chair in neuro-ophthalmology at the University of California, San Francisco, in his name. The chair will recognise Dr Hoyt's many contributions to the field of neuro-ophthalmology, including teaching, research, and clinical observations. People interested in obtaining further information regarding the chair should contact either Creig Hoyt, MD, at 400 Parnassus Avenue, Suite 704, San Francisco, California 94143, USA, or Neil R Miller, MD, Johns Hopkins Hospital, 600 North Wolfe Street, Wilmer Eye Institute, Maumenee Building B-107, Baltimore, Maryland 21205, USA.

\section{Canadian Ophthalmological Society}

The 50th Anniversary Meeting of the COS will be held on 20-23 June at the Queen Elizabeth Hotel, Montreal. Details from J Paul Le Bel, COS Executive Director, Ottawa, Ontario, or Cathy Hanson, Berger \& Associates Canada Inc., Toronto, Ontario, Canada. 